This item was submitted to Loughborough's Research Repository by the author.

Items in Figshare are protected by copyright, with all rights reserved, unless otherwise indicated.

\title{
Understanding of dynamic contacting behaviors of underwater gas bubbles on solid surfaces
}

PLEASE CITE THE PUBLISHED VERSION

https://doi.org/10.1021/acs.langmuir.0c01551

\section{PUBLISHER}

American Chemical Society (ACS)

\section{VERSION}

AM (Accepted Manuscript)

\section{PUBLISHER STATEMENT}

This document is the Accepted Manuscript version of a Published Work that appeared in final form in Langmuir, copyright $\odot$ American Chemical Society after peer review and technical editing by the publisher. To access the final edited and published work see https://pubs.acs.org/doi/10.1021/acs.langmuir.0c01551.

\section{LICENCE}

CC BY-NC-ND 4.0

\section{REPOSITORY RECORD}

Qin, Jingshan, Daojin Zhou, Fanhong Chen, Bairu Shi, Liang Luo, Anuj Kumar, Cheng Wang, et al.. 2020. "Understanding of Dynamic Contacting Behaviors of Underwater Gas Bubbles on Solid Surfaces". Loughborough University. https://hdl.handle.net/2134/12923165.v1. 


\section{Understanding of Dynamic Contacting Behaviors of Underwater Gas Bubbles on Solid Surfaces}

Jingshan Qin, Daojin Zhou, Fanhong Chen, Bairu Shi, Liang Luo, Anuj Kumar, Cheng Wang, Xiao Lin, Siyu Sheng, Wenwen Xu, Zhicheng Shang, Congtian Cheng, Yun Kuang, Wen-Feng Lin, Haijun Xu, and Xiaoming Sun

Langmuir, Just Accepted Manuscript • DOI: 10.1021/acs.langmuir.0c01551 • Publication Date (Web): 30 Aug 2020

Downloaded from pubs.acs.org on September 5, 2020

\section{Just Accepted}

"Just Accepted" manuscripts have been peer-reviewed and accepted for publication. They are posted online prior to technical editing, formatting for publication and author proofing. The American Chemical Society provides "Just Accepted" as a service to the research community to expedite the dissemination of scientific material as soon as possible after acceptance. "Just Accepted" manuscripts appear in full in PDF format accompanied by an HTML abstract. "Just Accepted" manuscripts have been fully peer reviewed, but should not be considered the official version of record. They are citable by the Digital Object Identifier (DOI®). "Just Accepted" is an optional service offered to authors. Therefore, the "Just Accepted" Web site may not include all articles that will be published in the journal. After a manuscript is technically edited and formatted, it will be removed from the "Just Accepted" Web site and published as an ASAP article. Note that technical editing may introduce minor changes to the manuscript text and/or graphics which could affect content, and all legal disclaimers and ethical guidelines that apply to the journal pertain. ACS cannot be held responsible for errors or consequences arising from the use of information contained in these "Just Accepted" manuscripts. 


\section{Understanding of Dynamic Contacting Behaviors of Underwater Gas Bubbles on Solid Surfaces}

Jingshan Qin, ${ }^{1, \dagger}$ Daojin Zhou, ${ }^{1, \dagger}$ Bairu Shi, ${ }^{2}$ Fanhong Chen, ${ }^{1}$ Liang Luo, ${ }^{1, *}$ Anuj Kumar, ${ }^{4}$ Cheng Wang, ${ }^{3}$ Xiao Lin, ${ }^{5}$ Siyu Sheng, ${ }^{1}$ Wenwen $\mathrm{Xu},{ }^{1}$ Zhicheng Shang, ${ }^{1}$ Congtian Cheng, ${ }^{1}$ Yun Kuang, ${ }^{1}$ Wen-Feng Lin, ${ }^{6}$ Haijun Xu, ${ }^{1, *}$ and Xiaoming Sun ${ }^{1, *}$ ${ }^{1}$ State Key Laboratory of Chemical Resource Engineering, Beijing Advanced Innovation Center for Soft Matter Science and Engineering, College of Chemistry, Beijing University of Chemical Technology, Beijing 100029, China

${ }^{2}$ Research Institute of Petroleum Exploration and Development, Beijing 100083, China

${ }^{3}$ Chinese Research Academy of Environmental Sciences, Beijing 100012, China

${ }^{4}$ GLA University, Mathura, UP -281406, India

${ }^{5}$ Department of Chemical Engineering and Biotechnology, University of Cambridge, Cambridge, CB3 0AS, UK

${ }^{6}$ Department of Chemical Engineering, Loughborough University, Loughborough, Leicestershire, LE11 3TU, UK 


\begin{abstract}
:
Understanding of dynamic behaviors of gas bubbles on solid surfaces has significant impacts on gas-involving electrochemical reactions, mineral flotation and so on in industry. Contact angle $(\theta)$ is widely employed to characterize the wetting behaviors of bubbles on solid surfaces; however, it usually fluctuates within the bubble's advancing $\left(\theta_{\mathrm{a}}\right)$ and receding $\left(\theta_{\mathrm{r}}\right)$ range. Although the term of most-stable contact angle $\left(\theta_{\mathrm{ms}}\right)$ was defined previously as the closest valuable approximation for thermodynamically meaningful contact angle for a droplet on solid surface, it has not been widely appreciated; and the precise $\theta_{\mathrm{ms}}$ measurement methods are inadequate to describe bubbles' wetting behaviors on solid surfaces. Herein, we proposed to take $\theta_{\mathrm{ms}}$ as the mean value of $\theta_{\mathrm{a}}$ and $\theta_{\mathrm{r}}$, as a more accurate descriptor of gas bubbles' dynamic behaviors on non-ideal solid surface, as similar to the definition of droplets' $\theta_{\mathrm{ms}}$ on solid surfaces. The feasibility and accuracy of the proposed $\theta_{\mathrm{ms}}$ have been evidenced by recording the bubbles' contacting behaviors on solid surfaces with varied wettabilities. In addition, it was found that the contact angle hysteresis $(\delta)$, as the difference between $\theta_{\mathrm{a}}$ and $\theta_{\mathrm{r}}$, reached its maximum value when $\theta_{\mathrm{ms}}$ approached to $90^{\circ}$, regardless of the roughness $(r)$ of substrates. Finally, built on the above concept, lateral adhesion force $(f)$ of gas bubble on solid interface, which worked on the three-phase contact line (TPCL) of individual bubble on a solid surface against its lateral motion during the bubble advancing or receding process, was described quantitatively by combining $\theta_{\mathrm{a}}, \theta_{\mathrm{r}}$ and liquid-gas interfacial tension $\left(\gamma_{\mathrm{lg}}\right)$. Experimental and theoretical data jointly confirmed that $f$ reached its maximum value at $\theta_{\mathrm{ms}} \sim 90^{\circ}$, namely the "super-sticky" state, which described the dynamically most sluggish movement of bubble along the solid surface.
\end{abstract}

Keywords: bubble, wettability, most-stable contact angle, lateral adhesion force, super-sticky state 


\section{INTRODUCTION}

Dynamic behaviors of underwater gas bubbles on solid surfaces have received vast interest from both fundamental and applied fields in the study of interface science. ${ }^{1-4}$ This topic is extremely important as it play key roles in the widely studied gas-involving reactions or processes. For example, gas evolution reaction efficiency will decrease sharply due to severe blocking of ionic reactants caused by gas bubbles' adhesion on electrode surfaces; ${ }^{5,6}$ vice versa, gas consumption reaction efficiency is also restricted by the gas diffusion in electrolyte owing to the rather limited solubility for most gaseous species; ${ }^{7-10}$ such gas-solid interactions also affect various applications such as mineral flotation, in which the interactions between bubble and mineral particles directly determine the flotation efficiency. ${ }^{11,12}$ Therefore, the wetting and adhesion behaviors of underwater gas bubbles on solid surfaces are fundamental to many gas-involving processes.

The wettability of underwater gas bubble on solid surface is generally described by the gas-solid adhesion force and contact angle $(\theta)$. The latter can be directly measured, and determined by classical Young's equation in a given gas-liquid-solid system using the three thermodynamic parameters, namely, liquid-gas $\left(\gamma_{\mathrm{lg}}\right)$, gas-solid $\left(\gamma_{\mathrm{gs}}\right)$ and liquid-solid $\left(\gamma_{\mathrm{ls}}\right)$ interfacial tensions. ${ }^{13,14}$ However, practical non-ideal surfaces determine that the measured contact angle is inconstant, always fluctuates between advancing contact angle $\left(\theta_{\mathrm{a}}\right)$ and receding contact angle $\left(\theta_{\mathrm{r}}\right)$, without relaxation or motion (assuming no dissolution occurs). ${ }^{15-18}$ In this context, considerable efforts have been devoted in establishing thermodynamic models and improving the measurement accuracy of contact angles of droplets on solid surfaces. ${ }^{19-21}$ A century ago, Adam et al. introduced $F$ as the friction force into Young's equation during the droplet advancing and receding processes, validating the well-known rule of equilibrium contact angle $\left(\theta_{\mathrm{e}}\right)$ as a mean value of cosine of $\theta_{\mathrm{a}}$ and $\theta_{\mathrm{r} .}{ }^{22}$ In addition, the contact angle hysteresis $(\delta)$ as the difference between $\theta_{\mathrm{a}}$ and $\theta_{\mathrm{r}}$ instead of $\theta$ has been used to characterize the wetting of solid by liquid. ${ }^{23,24}$ Recently, the most-stable contact angle $\left(\theta_{\mathrm{ms}}\right)$ of droplets has been evolved to precisely describe the interfacial wettability for droplets on solid surface, ${ }^{25,26}$ which can be regarded as the most approximation value for thermodynamically intrinsic contact angle of pinned 
bubble with the lowest Gibbs energy.

As the gravity of measured droplet with volume larger than $100 \mu \mathrm{L}$ will cause deviation in previse measuring contact angle ${ }^{27,28}$, similarly, the buoyancy influence should also be considered as a factor in bubble measurement, which would also bring the measurement difficulty. Considering the differences such as viscosity, density, visibility between bubble and droplet, not to mention the gas solubility and phase environment diversity, the precise measurement of bubble contact angle usually requires complicated instruments and is time consuming, which is quite limited in many application scenarios. ${ }^{29}$ Besides, there are also operational difficulties in placing precise instruments for in situ monitoring bubbles in a liquid phase environment to measure the lateral adhesion force $(f)$ by a series of well-developed methods, including the capillary displacement method, ${ }^{30}$ centrifugal adhesion balance method ${ }^{31}$ and nanotribometer method. ${ }^{32}$

Herein, we proposed $\theta_{\mathrm{ms}}$ as the mean value of $\theta_{\mathrm{a}}$ and $\theta_{\mathrm{r}}$ to simplify the characterization of the dynamic wetting behaviors of gas bubble on solid surface, and the reliability of $\theta_{\mathrm{ms}}$ was verified by recording $\theta_{\mathrm{a}}$ and $\theta_{\mathrm{r}}$ of gas bubbles on typical $\mathrm{Au}$, glass and one dimensional aligned patterned Si surfaces with different wettabilities and roughnesses. It was also found that the contact angle hysteresis $(\delta)$, as the difference between $\theta_{\mathrm{a}}$ and $\theta_{\mathrm{r}}$, reached its maximum value when $\theta_{\mathrm{ms}}$ approached to $90^{\circ}$, regardless of the roughness $(r)$ of substrates. Based on the verification of $\theta_{\mathrm{ms}}$, the lateral adhesion force $(f)$ on the bubble-solid surfaces was quantitatively described by combining $\theta_{\mathrm{a}}, \theta_{\mathrm{r}}$ and liquid-gas interfacial tension $\left(\gamma_{\mathrm{lg}}\right)$. In addition, the "super-sticky" state was found that presented a special point where the movement of gas bubbles on solid surface was mostly impeded. This work not only provided a simplified characterization method to accurately describe the wettability of underwater bubbles on solid surfaces, but also deepened the understanding of the dynamic behaviors of gas bubbles on solid/liquid interface.

\section{EXPERIENTAL SECTION}

Materials and instruments. Si wafer, $\mathrm{Au}$ (99.999\%) particles and $\mathrm{Cr}$ (99.99\%) rods were purchased from Haochen electromechanical Co. Ltd, China. Ethanol, 
hexadecanethiol and Teflon concentrationed solution (PTFE) were obtained from Beijing Chemical Works, China. The water used in the experiments was prepared through an ultra-pure purification system, and all the chemicals were used as received without further purification. Vacuum magnetism sputtering apparatus (SQC-310) was purchased from Braun, Germany.

Preparation of solid substrates with different wettabilities. The flat $50 \mathrm{~nm} \mathrm{Au}$ films were deposited on $5 \mathrm{~nm}$ Cr layer coated $\mathrm{Si}$ wafers under vacuum. In a typical process, Si wafers, Au particles and $\mathrm{Cr}$ rods were washed for ten times with ethanol and deionized water, respectively. The $5 \mathrm{~nm} \mathrm{Cr}$ layer was sputtered onto the Si wafer as adhesion layer before Au film deposition. Afterwards, the Au films were immersed in various hexadecanethiol solutions $(0 \sim 3 \mathrm{M})$ for about 1 hour and dried at $30{ }^{\circ} \mathrm{C}$ under vacuum to yield different wettabilities.

The structured patterns including precise sizes were obtained by photolithographic technology on Si wafers. Typically, the embossment widths and the groove depths were $10 \mu \mathrm{m}$ conformably, while the groove widths were $20,40,60$, and $80 \mu \mathrm{m}$, respectively. The as-prepared $\mathrm{Si}$ wafers patterns were soaked in $0.5 \mathrm{wt} \%$ of PTFE solution for 15 minutes, and then annealed at $350{ }^{\circ} \mathrm{C}$ for 30 minutes in $\mathrm{Ar}$ atmosphere to obtain the fluorinated Si wafers pattern. The inert gas Ar was used mainly to ensure that PTFE is not oxidized so that the solid surfaces were stained and the interface wettabilities were changed.

Contact angle measurement methods. The contact angles of bubbles on solid substrates were characterized by captive bubble method using the Dataphysics OCA20 system. The advancing and receding contact angles of underwater gas bubbles on the solid surfaces were measured by pinning an initial $4.0 \mu \mathrm{L}$ gas bubble firstly on the solid surface, then the volume of the bubble was increased or decreased with $0.1 \mu \mathrm{L} \mathrm{s}^{-1}$ dosing rate. The values of contact angles were obtained as the three-phase contact lines of bubbles moved with the varied bubble volumes.

\section{RESULTS AND DISCUSSION}



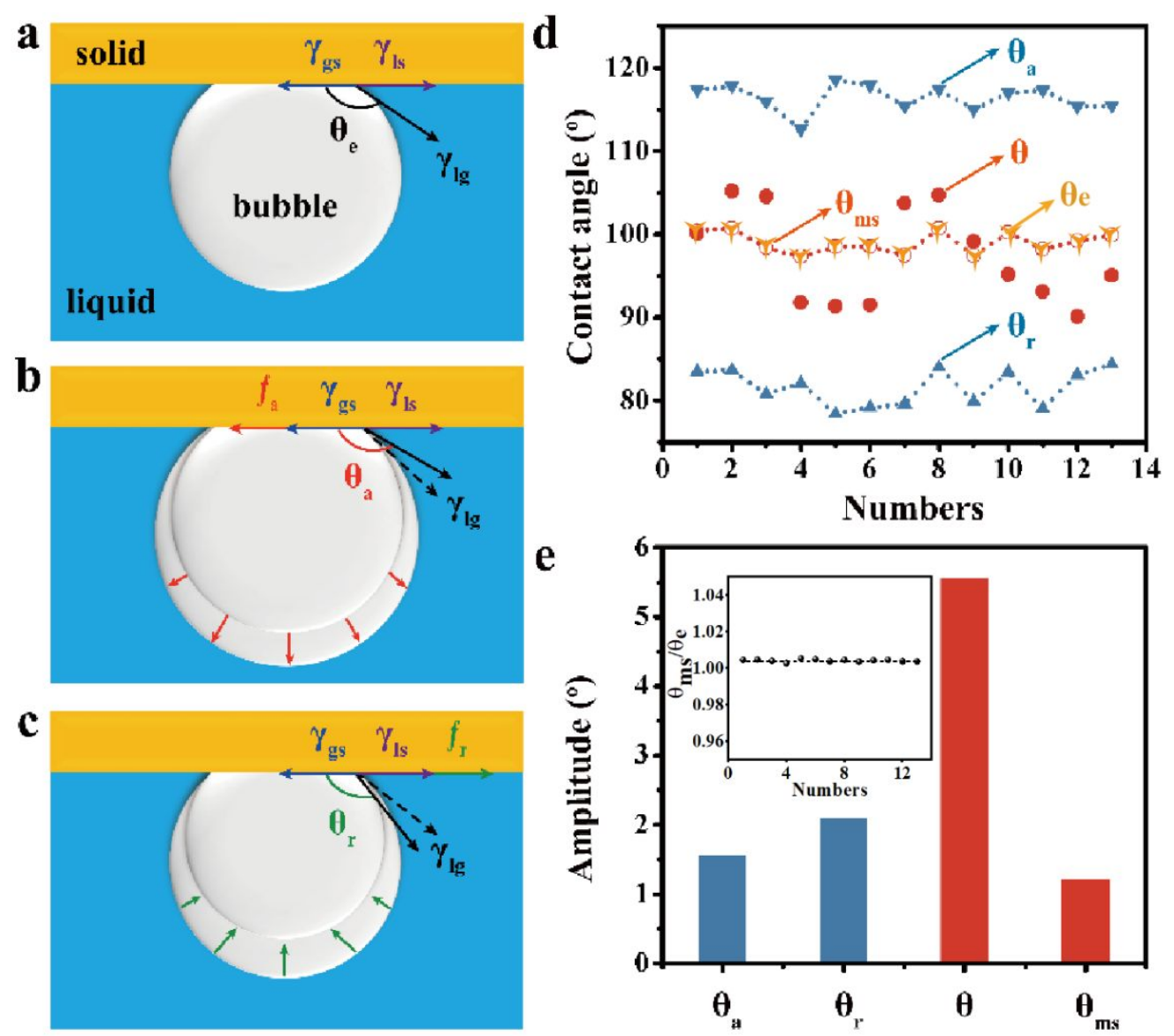

Figure 1. Schematic illustration of forces analysis for the underwater gas bubbles pinned on the solid surfaces: a) equilibrium state, b) advancing process, and c) receding process. d) The distribution of measured bubble $\theta, \theta_{\mathrm{a}}, \theta_{\mathrm{r}}, \theta_{\mathrm{e}}$ and $\theta_{\mathrm{ms}}$ on a given flat Au film surface. e) Comparisons of fluctuation amplitude by calculating the standard deviations of measured contact angles as shown in (d). Inset: the ratio distribution of bubble $\theta_{\mathrm{ms}}$ and $\theta_{\mathrm{e}}$.

The directly measured $\theta$ of bubble on solid surfaces fluctuates within the range of $\theta_{\mathrm{a}}$ and $\theta_{\mathrm{r}}$, which is not precise enough for effective analysis. Although $\theta_{\mathrm{e}}$ (Figure 1a) is meaningful, it is typically not experimentally accessible due to the difficulties in preparation of an ideal solid surface and maintaining equilibrium states during measurements. ${ }^{33,34}$ The highest apparent contact angle $\theta_{\mathrm{a}}$ was measured by increasing the volume of the bubble (Figure $1 \mathrm{~b}$ ), and the lowest apparent contact angle $\theta_{\mathrm{r}}$ was measured by decreasing the volume of the bubble (Figure 1c). ${ }^{19} \mathrm{Au}$ film was firstly chosen as a model surface owing to the chemical inert property and easy modification. By soaking in hexadecanethiol solution $(0 \sim 3 \mathrm{M})$ for 1 hour, $\mathrm{Au}$ film was endowed 
with a certain wettability, and typical snapshots of increasing and decreasing the volume of planted bubble on the as-treated $\mathrm{Au}$ film were recorded, as shown in Figure $\mathrm{S} 1$ and $\mathrm{S} 2$. As analyzed (Figure 1d), the measured $\theta_{\mathrm{a}}, \theta_{\mathrm{r}}$ (blue triangle dots) and $\theta$ (red solid dots) distributed in the range of $110 \sim 119^{\circ}, 77 \sim 85^{\circ}$ and $90 \sim 106^{\circ}$, respectively. It is obvious that there was big fluctuation for the as-measured $\theta$ with a standard deviation as large as $5.6^{\circ}$, indicating the large uncertainty in evaluating solid surface wettability only by direct measurement of contact angle. According to the previously defined relation of " $2 \cos \theta_{\mathrm{e}}=\cos \theta_{\mathrm{a}}+\cos \theta_{\mathrm{r}}$ ", ${ }^{22}$ we got the much more convergent distribution of $\theta_{\mathrm{e}}$ (orange stars), but the direct measurement of $\theta_{\mathrm{e}}$ can hardly be realized in practice. Instead of $\theta_{\mathrm{e}}$, we proposed the approximate $\theta_{\mathrm{ms}}$ as the mean value of $\theta_{\mathrm{a}}$ and $\theta_{\mathrm{r}}$ (eq 1 ) to simplify the evaluation of the non-ideal wettability of gas-solid interface, which was found to be mathematical accuracy $>94 \%$ (see more details in supporting information).

$$
\theta_{\mathrm{ms}}=\frac{\theta_{\mathrm{a}}+\theta_{\mathrm{r}}}{2}
$$

Accordingly, $\theta_{\mathrm{ms}}$ exhibited a rather limited standard deviation of $1.2^{\circ}$ (Figure $1 \mathrm{e}$ ), and ratio of $\theta_{\mathrm{ms}}$ to $\theta_{\mathrm{e}}$ (Figure 1e inset) clearly verified the high consistence between $\theta_{\mathrm{ms}}$ and $\theta_{\mathrm{e}}$.
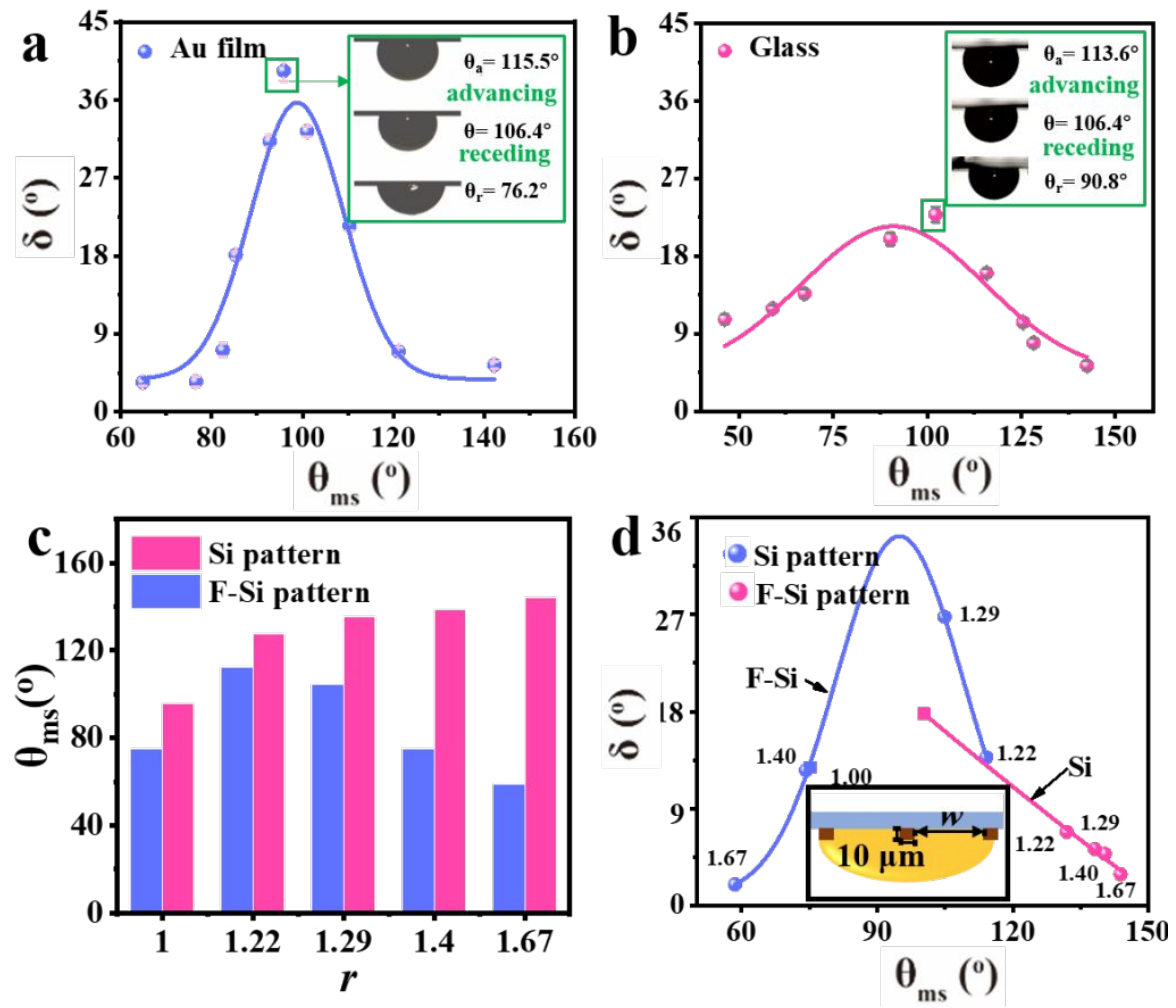
Figure 2. a) The relationship between $\theta_{\mathrm{ms}}$ and $\delta$ for bubbles on the Au film with the modulated wettabilities. Inset: The snapshots of varied states of bubble on a given Au film surface with the $\theta_{\mathrm{ms}} \sim$ $90^{\circ}$. b) The relationship between $\theta_{\mathrm{ms}}$ and $\delta$ for bubbles on glass film surfaces with the modulated wettabilities. Inset: The snapshots of varied states of bubble on a given Au film surface with the $\theta_{\mathrm{ms}} \sim$ $90^{\circ}$. c) The histogram of $\theta_{\mathrm{ms}}$ with $r$ on the structured micro-grooved Si and F-Si pattern surfaces. d) The plots of $\delta$ with $\theta_{\mathrm{ms}}$ variations for bubbles on the structured micro-grooved Si and F-Si pattern surfaces. The square points are $\delta$ of F-Si and Si surfaces. Solid line and dots are fitted and experimental results, respectively. Inset: The side view of the pattern surfaces.

Besides, $\delta$, as the difference between $\theta_{\mathrm{a}}$ and $\theta_{\mathrm{r}}$, is also an important factor as well as $\theta_{\mathrm{ms}}$ to characterize the interfacial wettability. By tuning the soaking time in thiol, the wettability of Au film can be easily tailored, as well as the glass in PTFE solution. Based on the varied wettabilities, $\theta, \theta_{\mathrm{a}}$ and $\theta_{\mathrm{r}}$ of underwater gas bubbles on Au films were found to change with the variation of $\theta_{\mathrm{ms}}$ (Figure S2), and the resultant $\delta$ of bubbles on the flat $\mathrm{Au}$ films (Figure 2a, pink points) increased first and then decreased as the increase of $\theta_{\mathrm{ms}}$, with the peak value of $39.3^{\circ}$ at $\theta_{\mathrm{ms}}=95.9^{\circ}, \theta_{\mathrm{a}}=115.5^{\circ}$ and $\theta_{\mathrm{r}}=76.2$. For the glass surfaces (Figure $2 \mathrm{~b}$, black points), $\delta$ exhibited similar variation with different wettabilities, with its maximum value of $22.8^{\circ}$ at $\theta_{\mathrm{ms}}=102.2^{\circ}$ where $\theta_{\mathrm{a}}=113.6^{\circ}, \theta_{\mathrm{r}}=90.8^{\circ}$.

To further verify the trends, we extended to the structured surfaces: one dimensional aligned patterned silicon (patterned Si) (Figure S3) and fluorinated (F-patterned Si) surfaces. The roughness factor $(r)$ can be clearly defined as the ratio of the real surface area to the apparent surface area, as expressed as $r=(30+w$ )$/(10+w)$ (Figure S4c) (where the embossment widths plus two times of the groove depths was $30 \mu \mathrm{m}$, the embossment widths was $10 \mu \mathrm{m}$, and the width (w) was 20, 40, 60 and $80 \mu \mathrm{m}$, respectively). ${ }^{35,36}$ Based on such patterned structures, there was an obvious change for the wettabilities with $r$ (Figure 2c). The intrinsic wettability of Si surface is aerophobic, as the groove width decreased, $\theta_{\mathrm{ms}}$ of bubbles on untreated patterned Si grew gradually, which can be attributed to the increase of the surface free energy on the patterned surface, namely, more and more aerophobic. After the PTFE modification, the intrinsic wettability of the obtained F-patterned Si surfaces became aerophilic $\left(75^{\circ}\right.$ for $\left.r=1\right)$. Further, $\theta_{\mathrm{ms}}$ of bubbles on the obtained F-patterned $\mathrm{Si}$ 
surfaces, as expected, became smaller and smaller with the decrease of groove width due to the decrease of the surface free energy, namely, more and more aerophilic. ${ }^{37}$ More importantly, $\delta$ also increased first and then decreased as the increase of $\theta_{\mathrm{ms}}$, and reached the maximum value $\left(28.8^{\circ}\right)$ when $\theta_{\mathrm{ms}}$ was close to $90^{\circ}\left(\theta_{\mathrm{ms}}=104.9^{\circ}\right.$ with $\theta_{\mathrm{a}}=119.3^{\circ}$ and $\theta_{\mathrm{r}}=90.5^{\circ}$ ) for patterned and un-patterned, fluorinated and un-fluorinated, rough and flat surfaces. In other words, the roughness factor $r$ determined the surface wettability $\left(\theta_{\mathrm{ms}}\right)$ and then affected $\delta$, and the contact angle hysteresis was the maximum when $\theta_{\mathrm{ms}}$ was nearly $90^{\circ}$. Noteworthy, for the extreme wettabilities, such as $\theta_{\mathrm{ms}}<50^{\circ}$, it would be obtained on nanoarray-based superaerophilic surfaces, which was difficult to define the roughness factor, but hardly be realized on smooth surface or ordinary micron array surfaces so that the precise values of $\theta_{\mathrm{a}}$ and $\theta_{\mathrm{r}}$ of such surfaces would be difficult to capture.

Moreover, the lateral adhesion force (f), impeding the TPCLs movement during the bubble advancing and receding processes, can be introduced into Young's equation to further describe the dynamic behaviors of bubbles on the solid surfaces. ${ }^{30-32,38}$ For equilibrium state, the three-phase interface tensions are well balanced according to Young's equation (eq 2) as there is no lateral adhesion force $(f=0)$;

$$
\gamma_{\mathrm{lg}} \cos \theta_{\mathrm{ms}}+\gamma_{\mathrm{gs}}=\gamma_{\mathrm{ls}}
$$

For nonequilibrium states, such as advancing and receding processes, $f_{\mathrm{a}}$ and $f_{\mathrm{r}}$ as advancing and receding lateral adhesion forces can be expressed as, ${ }^{39}$

$$
\begin{gathered}
\gamma_{\mathrm{lg}} \cos \theta_{\mathrm{a}}+\gamma_{\mathrm{gs}}+f_{\mathrm{a}}=\gamma_{\mathrm{ls}} \\
\gamma_{\mathrm{lg}} \cos \theta_{\mathrm{r}}+\gamma_{\mathrm{gs}}=\gamma_{\mathrm{ls}}+f_{\mathrm{r}}
\end{gathered}
$$

By solving eq 2 into eq 3 and 4 , we can get,

$$
\begin{aligned}
& f_{\mathrm{a}}=\gamma_{\mathrm{lg}}\left(\cos \theta_{\mathrm{ms}}-\cos \theta_{\mathrm{a}}\right) \\
& f_{\mathrm{r}}=\gamma_{\mathrm{lg}}\left(\cos \theta_{\mathrm{r}}-\cos \theta_{\mathrm{ms}}\right)
\end{aligned}
$$

Based on the definition of $\delta$, namely, $\delta=\theta_{\mathrm{a}}-\theta_{\mathrm{r}}$, eq 5 and 6 can be transformed as,

$$
\begin{aligned}
& f_{\mathrm{a}}=2 \gamma_{\mathrm{lg}} \sin \left(\theta_{\mathrm{ms}}+\frac{\delta}{4}\right) \sin \left(\frac{\delta}{4}\right) \\
& f_{\mathrm{r}}=2 \gamma_{\mathrm{lg}} \sin \left(\theta_{\mathrm{ms}}-\frac{\delta}{4}\right) \sin \left(\frac{\delta}{4}\right)
\end{aligned}
$$

where $\gamma_{\mathrm{gg}}, \gamma_{\mathrm{gs}}$ and $\gamma_{\mathrm{ls}}$ are liquid-gas, gas-solid and liquid-solid interfacial tension, respectively. $\gamma_{\mathrm{lg}}$ is $72 \mathrm{mN} \mathrm{m}^{-1}$ at room temperature. Generally, for rough surfaces, the real non-ideal contact area at the solid-liquid interface is larger than the apparent 
contact area. The apparent contact angle on rough surfaces can be expressed with the intrinsic contact angle on flat surfaces according to Wenzel equation $\left(\cos \theta^{\prime}=r \cos \theta\right.$, where $r$ is the roughness factor, $r \geq 1$ ). Thus, we can also get the modified mathematical relationship of lateral adhesion forces as demonstrated in eq S10, S11 $\left(f_{\mathrm{a}}=r f_{\mathrm{a}}, f_{\mathrm{r}}=r f_{\mathrm{r}}\right)$ for rough surfaces.
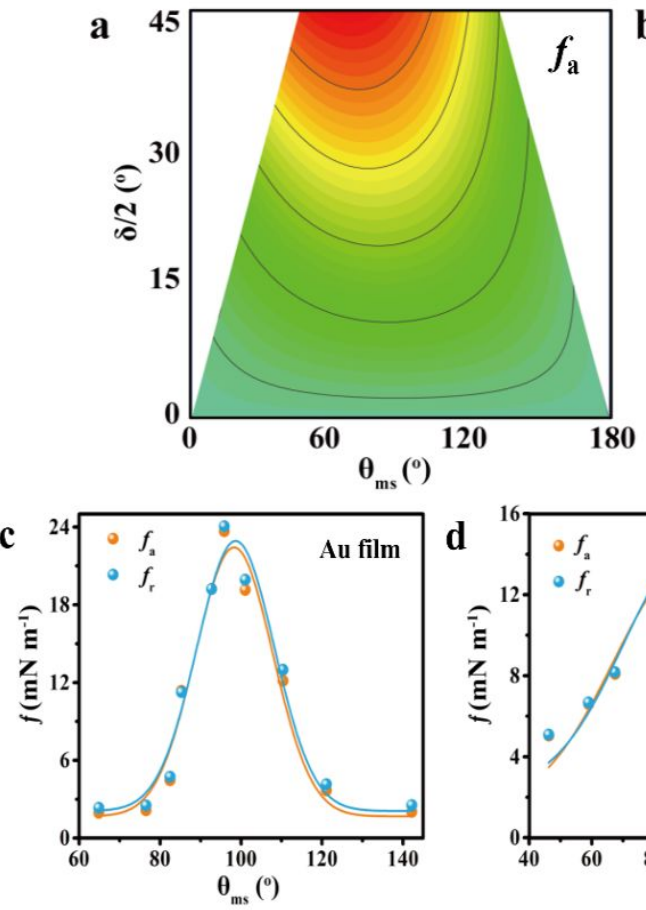
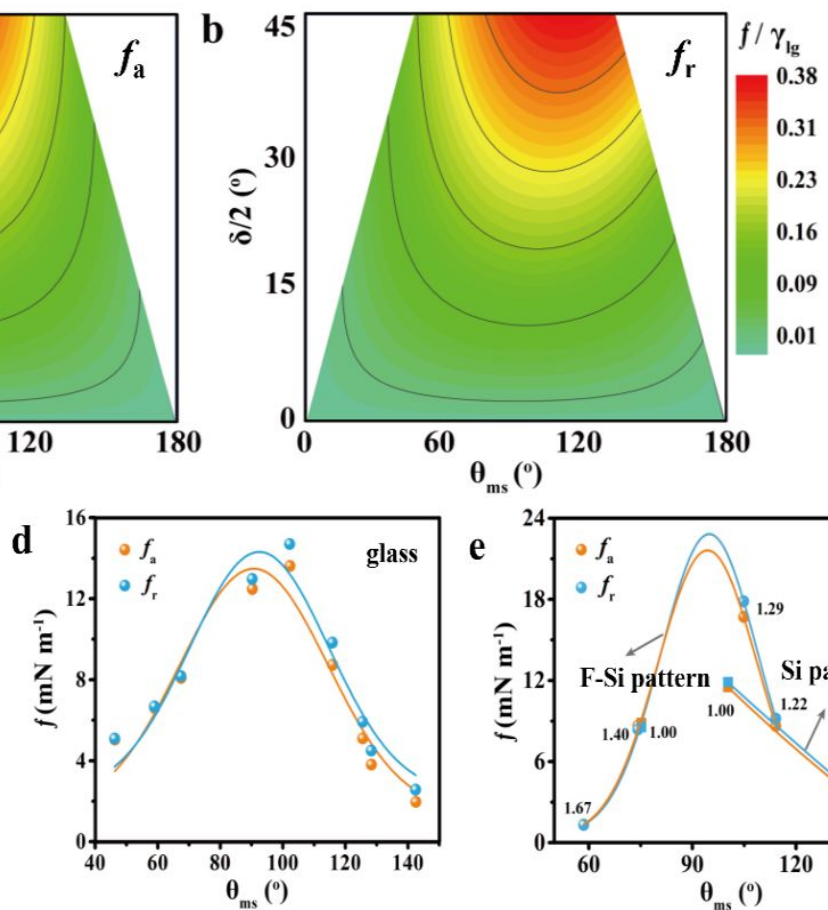

Figure 3. Numerical simulation of the relationship between $f, \delta$ and $\theta_{\mathrm{ms}}$ : a) advancing and $\mathrm{b}$ ) receding processes for bubbles on the solid surfaces with different wettabilities. c, d, e) Plots of $f$ as a function of $\theta_{\mathrm{ms}}$ for bubbles on the Au films, glass and structured micro-grooved $\mathrm{Si}$ and F-Si pattern surfaces with varied wettabilities during the bubble advancing and receding processes, respectively.

In light of the relationship between $f, \delta$ and $\theta_{\mathrm{ms}}$ as demonstrated in eq 7 and 8 , the related functions for advancing and receding processes were programmed by $\operatorname{MATLAB}\left(\delta / 2\right.$ was set as between $0^{\circ}$ and $45^{\circ}$ ) as shown in Figure $3 \mathrm{a}$ and $\mathrm{b}$, respectively. The abscissa and ordinate showed all mathematical combinations of $\delta$ and $\theta_{\mathrm{ms}}$ for bubbles on the solid surfaces. Once $\delta$ and $\theta_{\mathrm{ms}}$ are obtained, the value of $f$ can be determined intuitively from the color distribution based on the numerical simulation. According to the as-marked color scale, we can clearly get the distribution of theoretical values $f$. Typically, $f_{\mathrm{a}}$ would reach the maximum value as $\delta / 2$ was $45^{\circ}$ and $\theta_{\mathrm{ms}}$ was $67.5^{\circ}$, and $f_{\mathrm{r}}$ would reach its maximum value as $\delta / 2$ and $\theta_{\mathrm{ms}}$ were $45^{\circ}$ and $112.5^{\circ}$, respectively. There was a little difference for the value distributions between $f_{\mathrm{a}}$ 
and $f_{\mathrm{r}}$ due to the different processes of advancing and receding. As $\delta$ was close to 0 and $\theta_{\mathrm{ms}}$ was greater than $120^{\circ}$ or less than $60^{\circ}, f$ became rather limited. Based on the experimental results (Figure $2 \mathrm{a}$ and $2 \mathrm{c}$ ), we found that the maximum value of $f_{\mathrm{a}}$ was $23.68 \mathrm{mN} \mathrm{m}^{-1}$ and $f_{\mathrm{r}}$ was $24.53 \mathrm{mN} \mathrm{m}^{-1}$ as $\delta / 2=19.7^{\circ}$ and $\theta_{\mathrm{ms}}=95.9^{\circ}$ for $\mathrm{Au}$ film (Figure 3c), and $13.62 \mathrm{mN} \mathrm{m}^{-1}\left(f_{\mathrm{a}}\right)$ and $14.22 \mathrm{mN} \mathrm{m}^{-1}\left(f_{\mathrm{r}}\right)$ as $\delta / 2=9.5^{\circ}$ and $\theta_{\mathrm{ms}}=102.2^{\circ}$ for glass surface (Figure 3d). The experimental results of the dependence of $\theta_{\mathrm{ms}}$ and $f$ on flat surfaces were in highly accord with the numerical simulation (Figure $3 a, b$ ).

Such relationship for bubbles on structured surfaces was also verified. Figure $3 \mathrm{e}$ plots a function of bubble $\theta_{\mathrm{ms}}$ on the patterned Si and F-patterned Si surfaces, where the viewing direction was parallel to the one dimensional aligned grooves (Figure $\mathrm{S} 4 \mathrm{c})$. On the patterned Si surface, the bubble movement became easier with larger $r$ due to the larger surface free energy, as evidenced by the decrease of $f_{\mathrm{a}}$ from $11.5 \mathrm{mN}$ $\mathrm{m}^{-1}$ to $1.8 \mathrm{mN} \mathrm{m}^{-1}$, as well as the decrease of $f_{\mathrm{r}}$ from $11.9 \mathrm{~m} \mathrm{~m}^{-1}$ to $1.9 \mathrm{mN} \mathrm{m}^{-1}$ with increasing $r$ from 1 to 1.67. For the F-patterned Si surfaces, the maximum values of $16.7 \mathrm{mN} \mathrm{m}^{-1}$ and $17.9 \mathrm{mN} \mathrm{m}^{-1}$ for $f_{\mathrm{a}}$ and $f_{\mathrm{r}}$ were gained at $r=1.29$ for bubble (Figure $3 \mathrm{e})$. This was because $f_{\mathrm{a}}$ was directly related to $\theta_{\mathrm{ms}}$, while $r$ in company with surface chemical property played significant roles in affecting the value of $\theta_{\mathrm{ms}}$. More importantly, the maximum $f_{\mathrm{a}}\left(16.7 \mathrm{mN} \mathrm{m}^{-1}\right)$ and $f_{\mathrm{r}}\left(17.9 \mathrm{mN} \mathrm{m}^{-1}\right)$ reached at $\theta_{\mathrm{ms}}=104.9^{\circ}$ closing to $90^{\circ}$. Although there were different values of $f$ with the variation of $r$ for $\mathrm{Au}$ films, glass, and patterned Si surfaces, the maximum values of $f$ centered at almost the same location $\left(\theta_{\mathrm{ms}} \approx 90^{\circ}\right)$, where $\cos \theta_{\mathrm{ms}} \approx 0$, and $\gamma_{\mathrm{gs}} \approx \gamma_{\mathrm{ls}}$. That was a special state where the movement of TPCLs induced by changing bubble volume is of most difficulty, which was thus described as a "super-sticky" state.
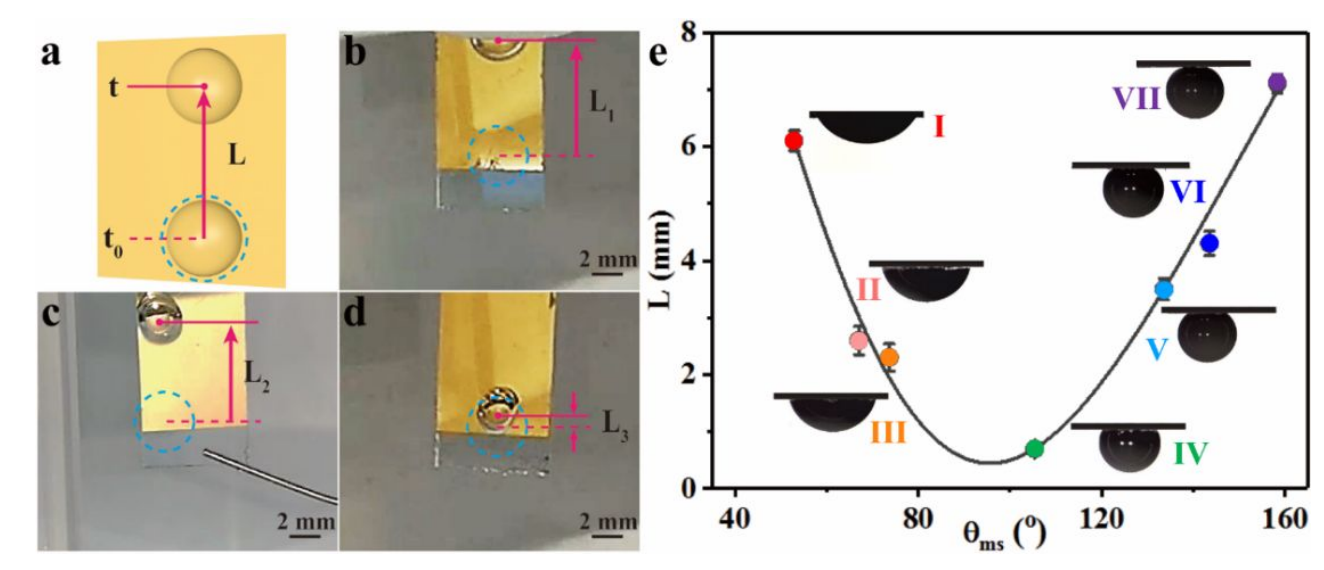
Figure 4. a) Schematic illustration of the sliding distance $(L)$ at the time slots $\left(t-t_{0}\right)$ for underwater gas bubbles adhering on vertical Au film surfaces. The sliding distance within 5 seconds of underwater bubbles on $\mathrm{Au}$ film surfaces with $\theta_{\mathrm{ms}}:$ b) $158.3^{\circ}$, c) $52.9^{\circ}$, and d) $105.4^{\circ}$. e) Plot of $\mathrm{L}$ as a function of $\theta_{\mathrm{ms}}$ for the evolution of underwater gas bubbles. The inserts are snapshots of bubble contact angle on the Au surfaces having different wettabilities.

The "super-sticky" state at $\theta_{\mathrm{ms}}=90^{\circ}$ was further demonstrated through underwater bubble-sliding experiments carried out on vertical flat $\mathrm{Au}$ film surfaces. The sliding distances (L) from the initial bubble touching spots on flat Au film surfaces with different wettabilities at given time slots $\left(\mathrm{t}-\mathrm{t}_{\mathrm{o}}=5 \mathrm{~s}\right)$ were measured and compared (schematically shown in Figure $4 \mathrm{a}$ ). $\theta, \theta_{\mathrm{a}}$, and $\theta_{\mathrm{r}}$ of underwater bubbles on several surfaces with different wettabilities were measured and summarized in Figure S5. The sliding distance for the bubbles at the Au film surface with $\theta_{\mathrm{ms}}=158.3^{\circ}$ (Figure $4 \mathrm{~b}$ ) was found to be the maximum with $7.2 \mathrm{~mm}$, while the sliding distance $\mathrm{L}_{2}=6.6 \mathrm{~mm}$ was observed for bubble on Au surface with $\theta_{\mathrm{ms}}=52.9^{\circ}$ (Figure 4c). Compared with aerophobic or aerophilic cases, the bubble almost kept still with rather limited $\mathrm{L}_{3}=0.9$ $\mathrm{mm}$ at $\theta_{\mathrm{ms}}=105.4^{\circ}$ (Figure $4 \mathrm{~d}$ ). The bubbles' sliding distance $\mathrm{L}$ at other wettability states is presented in the Figure S6. It is worth noting that L decreased sharply with the increase of $\theta_{\mathrm{ms}}$ from 52.9 to $105.4^{\circ}$, then it gradually increased again with further increase $\theta_{\mathrm{ms}}$ up to $158.3^{\circ}$ (Figure 4e). These phenomena of bubble-sliding further confirmed the strongest interaction at the TPCLs between the solid surface and the underwater bubble in the "super-sticky" state when $\theta_{\mathrm{ms}}$ approached to $90^{\circ}$. The original movies of underwater gas bubbles sliding on the Au film surfaces with the $\theta_{\mathrm{ms}}$ at $158.3^{\circ}, 52.9^{\circ}$ and $105.4^{\circ}$ are displayed in the supporting information.

\section{CONCLUSION}

The most-stable contact angle, $\theta_{\mathrm{ms}}$, was proposed to take the mean value of the bubble's advancing $\left(\theta_{\mathrm{a}}\right)$ and receding $\left(\theta_{\mathrm{r}}\right)$ contact angles, to serve as a more accurate descriptor of gas bubble's dynamic behaviors on a non-ideal solid surface under a liquid environment, as being similar to the definition of a droplet's $\theta_{\mathrm{ms}}$ on a solid surface. The $\theta_{\mathrm{ms}}$ was employed to accurately assess the interfacial wettability between 
gas bubbles and solid surfaces, overcoming the uncertainty of interfacial wettability description due to fluctuating of contact angle $(\theta)$ in the range between $\theta_{\mathrm{a}}$ and $\theta_{\mathrm{r}}$. Experiments confirmed that $\theta_{\mathrm{ms}}$ as arithmetic mean value of $\theta_{\mathrm{a}}$ and $\theta_{\mathrm{r}}$, is a simpler and more reliable method compared to that of direct measurement which coupled with complex instruments and involved large operating errors. Furthermore, by recording the $\theta_{\mathrm{a}}$ and $\theta_{\mathrm{r}}$ of bubbles on the solid surfaces with modulated wettabilities, and from the dependency of the contact angle hysteresis $\delta$ and $\theta_{\mathrm{ms}}$, it was found that $\delta$ reached its apex at $\theta_{\mathrm{ms}} \sim 90^{\circ}$. The dependence of $\delta$ on $\theta_{\mathrm{ms}}$ remained constant for bubbles on the substrates with varied roughness factor, although $\delta$ was changing even at the same roughness factor. Considering the relationship between $\theta_{\mathrm{ms}}$ and $\delta$, the lateral adhesion force $(f)$ of gas bubble on solid interface, which worked on the three-phase contact line (TPCL) of individual bubble on a solid surface against its lateral motion during the bubble advancing or receding process, was described quantitatively by combining $\theta_{\mathrm{a}}, \theta_{\mathrm{r}}$ and liquid-gas interfacial tension $\left(\gamma_{\mathrm{lg}}\right)$. Experimental and theoretical data jointly confirmed that $f$ reached its maximum value at $\theta_{\mathrm{ms}} \sim 90^{\circ}$, namely the "super-sticky" state, which described the dynamically most sluggish movement of bubble along the solid surface. The definition of "super-sticky" state of bubble on solid surfaces has an insightful implication for the design of micro-structured device for gas transportation and collection. This work not only provides a characterization method for accurately describing wetting interactions of gas-liquid, but also deepens the understanding of gas bubble's dynamic evolution behaviors on the solid surfaces under liquid environment and provides a theoretical basis for structure design of special wetting interface.

\section{ASSOCIATED CONTENT}

\section{Supporting Information}

Figure S1. Snapshots of underwater gas bubble's contact angle $(\theta)$, advancing contact angle $\left(\theta_{\mathrm{a}}\right)$ and receding contact angle $\left(\theta_{\mathrm{r}}\right)$, pinned on a given flat Au film surface.

Figure S2. Snapshots of underwater gas bubble's contact angles pinned on the Au film surfaces with different wettability states. 
Figure S3. The SEM images of structured silicon wafer pattern surfaces with different sizes. Typically, the embossment widths and the groove depths are $10 \mu \mathrm{m}$ conformably, the groove widths (w) are $20,40,60$, and $80 \mu \mathrm{m}$ as shown in a, b, c, d), respectively.

Figure S4. a) Plots of $\delta$ with $\theta_{\mathrm{ms}}$ from different viewing directions on F-Si pattern surfaces. The red points are the results of observing vertical to grooves and the blue points are the results of observing parallel to grooves. b) The side view of the structured silicon surfaces. Typically, the embossment widths and the groove depths are $10 \mu \mathrm{m}$ conformably, the groove widths (w) are 20,40,60, and $80 \mu \mathrm{m}$. c) Abridged general view and snapshots of underwater gas bubbles from different viewing directions on the structured silicon surface with $r=1.40$.

Figure S5. Snapshots of underwater gas bubbles with various $\theta, \theta_{\mathrm{a}}$ and $\theta_{\mathrm{r}}$ on the $\mathrm{Au}$ film surfaces with different wettabilities.

Figure S6. The sliding distance (L) within 5 seconds of underwater gas bubbles on vertical $\mathrm{Au}$ film surfaces with different $\theta_{\mathrm{ms}}$ : a) $143.5^{\circ}$, b) $133.6^{\circ}$, c) $73.7^{\circ}$, and d) $67.0^{\circ}$.

The deduction of $\theta_{\mathrm{ms}}$ as a mean value of $\theta_{\mathrm{a}}$ and $\theta_{\mathrm{r}}$ describing the wettability of gas-solid

The deduction of advancing lateral adhesion force $\left(f_{\mathrm{a}}\right)$ and the receding lateral adhesion force $\left(f_{\mathrm{r}}\right)$ on rough surfaces

Supporting Movie 1. The measurement of bubble sliding distance on the Au film surface with the $\theta_{\mathrm{ms}}=52.9^{\circ}$.

Supporting Movie 2. The measurement of bubble sliding distance on the Au film surface with the $\theta_{\mathrm{ms}}=105.4^{\circ}$.

Supporting Movie 3. The measurement of bubble sliding distance on the Au film surface with the $\theta_{\mathrm{ms}}=158.3^{\circ}$.

\section{AUTHOR IMFORMATION}




\author{
Corresponding Authors \\ *E-mail: luoliang@mail.buct.edu.cn (Liang Luo) \\ *E-mail: hjxu@mail.buct.edu.cn (Haijun Xu) \\ *E-mail: sunxm@mail.buct.edu.cn (Xiaoming Sun)

\section{ORCID}

Liang Luo: 0000-0002-1739-4996

Xiaoming Sun: 0000-0002-3831-6233

\title{
Author Contributions
}

Liang Luo, Xiaoming Sun, Daojin Zhou and Haijun $\mathrm{Xu}$ designed the experiments; Jingshan Qin, Bairu Shi, Daojin Zhou, Fanhong Chen, Siyu Sheng, Zhicheng Shang and Congtian Cheng performed the experiments; Liang Luo, Haijun Xu, Yun Kuang, Wen-Feng Lin, Wenwen $\mathrm{Xu}$ and Cheng Wang provided advice; Daojin Zhou, Jingshan Qin, Fanhong Chen and Wen-Feng Lin drafted the manuscript; Xiaoming Sun, Anuj Kumar, Xiao Lin, Liang Luo and Wen-Feng Lin discussed the data and revised the manuscript. Jingshan Qin and Daojin Zhou contributed equally to this work.

\section{Notes}

The authors declare no competing financial interest.

\section{ACKNOWLEDGEMENTS}

This work was supported by the National Natural Science Foundation of China (NSFC), the National Key Research and Development Project (No. 2018YFB1502401, 2018YFA0702002), the Royal Society and the Newton Fund through the Newton Advanced Fellowship award (NAF\R1\191294), the Program for Changjiang Scholars and Innovation Research Team in the University (No. IRT1205), the Fundamental Research Funds for the Central Universities, and the long-term subsidy mechanism from the Ministry of Finance and the Ministry of Education of PRC. 


\section{REFERENCES}

(1) Wang, S.; Liu, K.; Yao, X.; Jiang, L. Bioinspired surfaces with superwettability: New insight on theory, design, and applications. Chem. Rev. 2015, 115, 8230-8293.

(2) He, Z.; Liu, K.; Wang, J. Bioinspired materials for controlling ice nucleation, growth, and recrystallization. Acc. Chem. Res. 2018, 51, 1082-1091.

(3) Yu, C.; Zhang, P.; Wang, J.; Jiang, L. Superwettability of gas bubbles and its application: From bioinspiration to advanced materials. Adv. Mater. 2017, 29, 1703053.

(4) Wen, L.; Tian, Y.; Jiang, L. Bioinspired super-wettability from fundamental research to practical applications. Angew. Chem. Int. Ed. 2015, 54, 3387-3399.

(5) Han, N.; Yang, K.; Lu, Z.; Li, Y.; Xu, W.; Gao, T.; Cai, Z.; Zhang, Y.; Batista, V. S.; Liu, W.; Sun, X. Nitrogen-doped tungsten carbide nanoarray as an efficient bifunctional electrocatalyst for water splitting in acid. Nat. Commun. 2018, 9, 924.

(6) Xu, W.; Lu, Z.; Sun, X.; Jiang L.; Duan X. Superwetting electrodes for gas-involving electrocatalysis. Acc. Chem. Res. 2018, 51, 1590-1598.

(7) Liu, M.; Wang, S.; Jiang, L. Nature-inspired superwettability systems. Nat. Rev. Mater. 2017, 2, 17036.

(8) Lu, Z.; Zhu, W.; Yu, X.; Zhang, H.; Li, Y.; Sun, X.; Wang, X.; Wang, H.; Wang, J.; Luo, J.; Lei, X.; Jiang, L. Ultrahigh hydrogen evolution performance of under-water "superaerophobic" $\operatorname{mos}_{2}$ nanostructured electrodes. Adv. Mater. 2014, 26, 2683-2687.

(9) Trogadas, P.; Ramani, V.; Strasser P.; Fuller, T. F.; Coppens, M. O. Hierarchically structured nanomaterials for electrochemical energy conversion. Angew. Chem. Int. Ed. 2016, 55, 122-148.

(10) Lu, Z.; Xu, W.; Ma, J.; Li, Y.; Sun, X.; Jiang, L. Superaerophilic carbon-nanotube-array electrode for high-performance oxygen reduction reaction. Adv. Mater. 2016, 28, 7155-7161.

(11) Parmigiani A.; Faroughi S.; Huber C.; Bachman, O.; Su Y. Bubble accumulation and its role in the evolution of magma reservoirs in the upper crust. Nature 2016, 532, 492-495. 
(12) Mungall, J. E.; Brenan, J. M.; Godel, B.; Barnes, S. J.; Gaillard, F. Transport of metals and sulphur in magmas by flotation of sulphide melt on vapour bubbles. Nat. Geosci. 2015, 8, 216-219.

(13) Young T. An essay on the cohesion of fluids. Roy Soc (London) 1805, 95, 65-87.

(14) Yong, J.; Chen, F.; Fang, Y.; Huo, J.; Yang, Q.; Zhang, J.; Bian, H.; Hou, X. Bioinspired design of underwater superaerophobic and superaerophilic surfaces by femtosecond laser ablation for anti- or capturing bubbles. ACS Appl. Mater. Interfaces 2017, 9, 39863-39871.

(15) Gao L.; McCarthy, T. J. Contact angle hysteresis explained. Langmuir 2006, 22, 6234-6237.

(16) Eral, H. B.; Mannetje, D. J. C. M. A.; Oh, J. M. Contact angle hysteresis: a review of fundamentals and applications. Colloid. Polym. Sci. 2013, 291, 247-260.

(17) Chibowski, E. On some relations between advancing, receding and Young's contact angles. Adv. Colloid Interface Sci. 2007, 133, 51-59.

(18) Chibowski, E.; Ontiveros-ortega, A.; Perea-carpio, R. On the interpretation of contact angle hysteresis. J. Adhesion Sci. Technol. 2002, 16, 1367-1404.

(19) Drelich, J. W. Contact angles: From past mistakes to new developments through liquid-solid adhesion measurements. Adv. Colloid Interface Sci. 2019, 267, 1-14.

(20) Jiang, M.; Zhou, B.; Wang, X. Comparisons and validations of contact angle models. Int. J. Hydrogen Energy 2018, 43, 6364-6378.

(21) Kalantarian, A.; David, R.; Neumann, A. W. Methodology for high accuracy contact angle measurement. Langmuir 2009, 25, 14146-14154.

(22) Adam, N. K.; Jessop, G. Angles of contact and polarity of solid surfaces. J. Chem. Soc. Trans. 1925, $127,1863-1868$.

(23) Yuan, Y.; Lee, T. R. Contact angle and wetting properties. Berlin: Surf Sci Springer. 2013, 3-34.

(24) Koishi, T.; Yasuoka, K.; Fujikawa, S.; Zeng X. Measurement of contact-angle hysteresis for droplets on nanopillared surface and in the cassie and wenzel states: A molecular dynamics simulation study. ACS Nano 2011, 5, 6834-6842.

(25) Marmur, A.; Volape, C. D.; Siboni, S.; Amirfazli, A.; Dielich, J. W. Contact angles and wettability: 
towards common and accurate terminology. Surf. Innov. 2017, 5, 3-8.

(26) Siddiqui, M. A. Q.; Ali, S.; Fei, H.; Roshan, H. Current understanding of shale wettability: A review on contact angle measurements. Earth Sci. Rev. 2018, 181, 1-11

(27) Zhao, T.; Jiang, L.Contact angel measurement of natural materals. Colloids Surf. B Biointerfaces 2018, 161, 324-330.

(28) Zhao, B.; Wang, X.; Wang, S.; Tai, R.; Zhang, L.; Hu, J. In site measurement of contct angles and surface tensions of interfacial nanobubbles in ethanol aqueous solutions. Soft Matt. 2016, 12, 3303.

(29) Montes Ruiz-Cabello, F. J.; Rodriguez-Valverde, M. A.; Cabrerizo-Vilchez, M. A. Equilibrium contact angle or the most-stable contact angle? Adv. Colloid Interface Sci. 2014, 206, 320-327.

(30) Gao N.; Geyer F.; Pilat DW.; Wooh, S.; Vollmer, D.; Butt, H. J.; Berger, R. How drops start sliding over solid surfaces. Nat. Phys. 2017, 14, 191-196.

(31) Tadmor, R.; Bahadur, P.; Leh, A.; N'guessan, H. E.; Jaini, R.; Dang, L. Measurement of lateral adhesion forces at the interface between a liquid drop and a substrate. Phys. Rev. Lett. 2009, 103, 266101.

(32) Qiao, S.; Li, S.; Li, Q.; Li, B.; Liu, K.; Feng, X. Friction of Droplets Sliding on Microstructured Superhydrophobic Surfaces. Langmuir 2017, 33, 13480-13489.

(33) Bormashenko, E. Wetting of real solid surfaces:new glance on well-known problems. Colloid. Polym. Sci. 2013, 291, 339-342.

(34) Tommi, H.; Xuelin, T.; Korhonen, J. T.; Ras, R. H. A. Surface-wetting characterization using contact-angle measurements. Nat. Protoc. 2018, 13, 1521-1538.

(35) Kang, H. C.; Jacobi, A. M. Equilibrium contact angles of liquid droplets on ideal rough solids. Langmuir 2011, 27, 4910-14918.

(36) Zhang, P.; Wang, S.; Wang, S.; Jiang, L. Superwetting surfaces under different media:Effects of surface topography on wettability. Small 2015, 11, 1939-1946.

(37) Wang, S.; Liu, K.; Yao, X.; Jiang, L. Bioinspired surfaces with superwettability: New insight on theory, design, and applications. Chem. Rev. 2015, 16, 8230-8293. 
(38) Pilat, D. W.; Papadopoulous, P.; Schaffff el, D.; Vollmer, D.; Berger, R.; Butt, H. J. Dynamic measurement of the force required to move a liquid drop on a solid surface. Langmuir 2012, 28, $16812-16820$.

(39) Jiang, Y.; Xu, W.; Sarshar, M. A.; Choi, C. H. Generalized models for advacning and receding contact angles of fakir droplets on pillared and pored surfaces. J. Colloid Inetrface Sci. 2019, 552, $359-371$. 
For Table of Contents Use Only
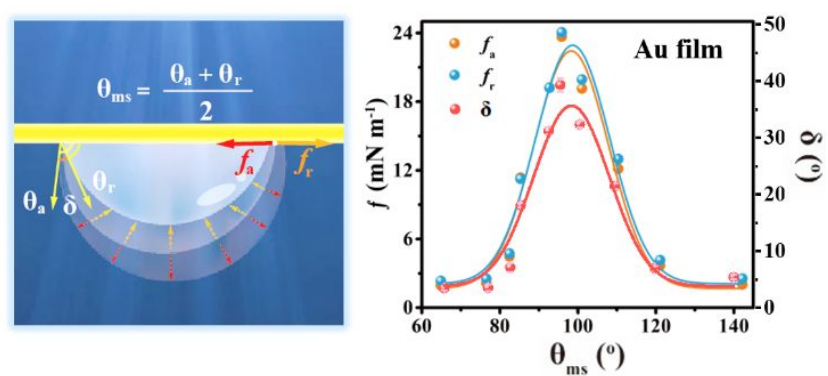

15

16

17 

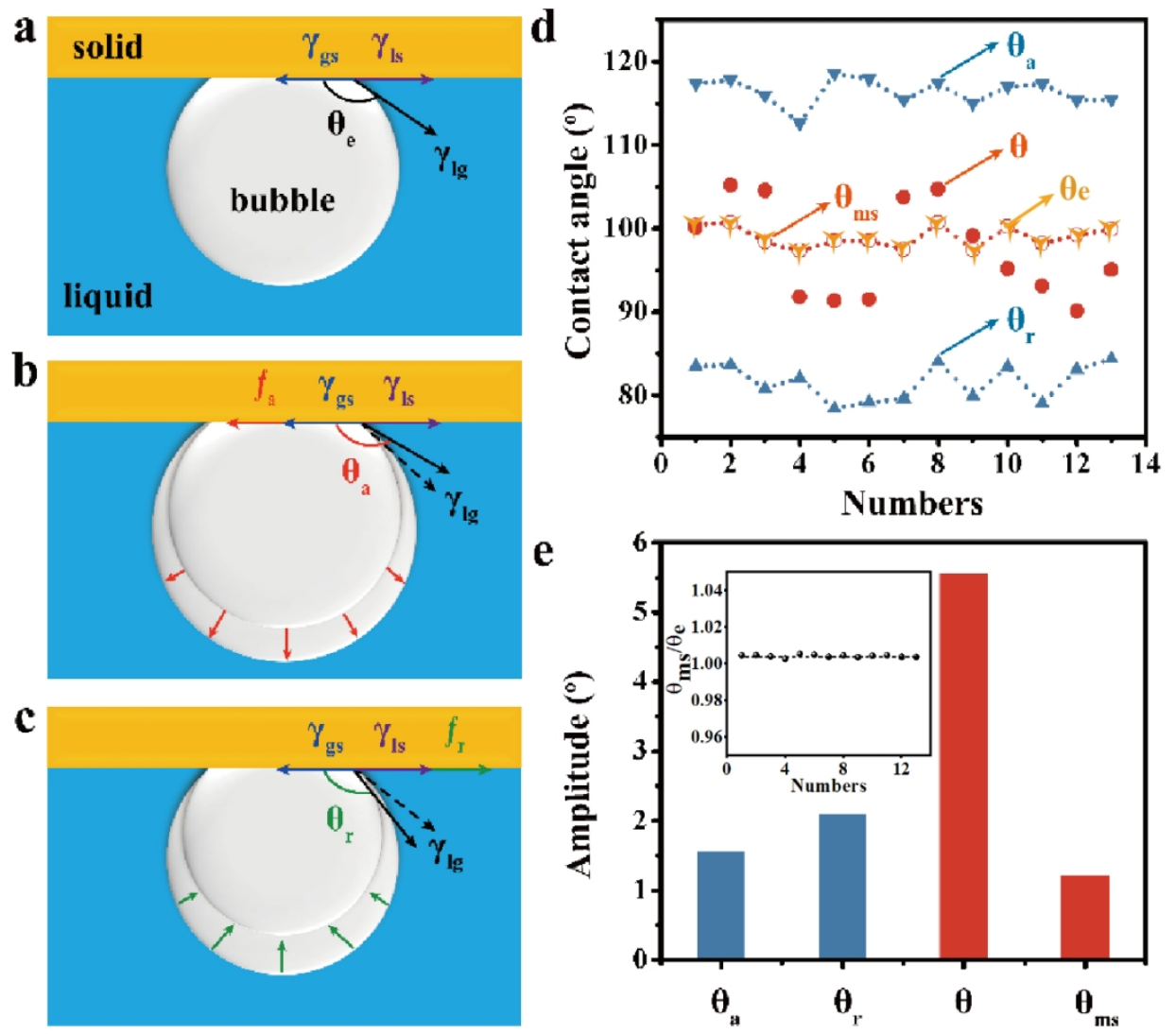

Figure 1. Schematic illustration of forces analysis for the underwater gas bubbles pinned on the solid surfaces: a) equilibrium state, b) advancing process, and c) receding process. d) The distribution of measured bubble $\theta, \theta a, \theta r, \theta e$ and $\theta$ ms on a given flat Au film surface. e) Comparisons of fluctuation amplitude by calculating the standard deviations of measured contact angles as shown in (d). Inset: the ratio distribution of bubble $\theta \mathrm{ms}$ and $\theta \mathrm{e}$. 

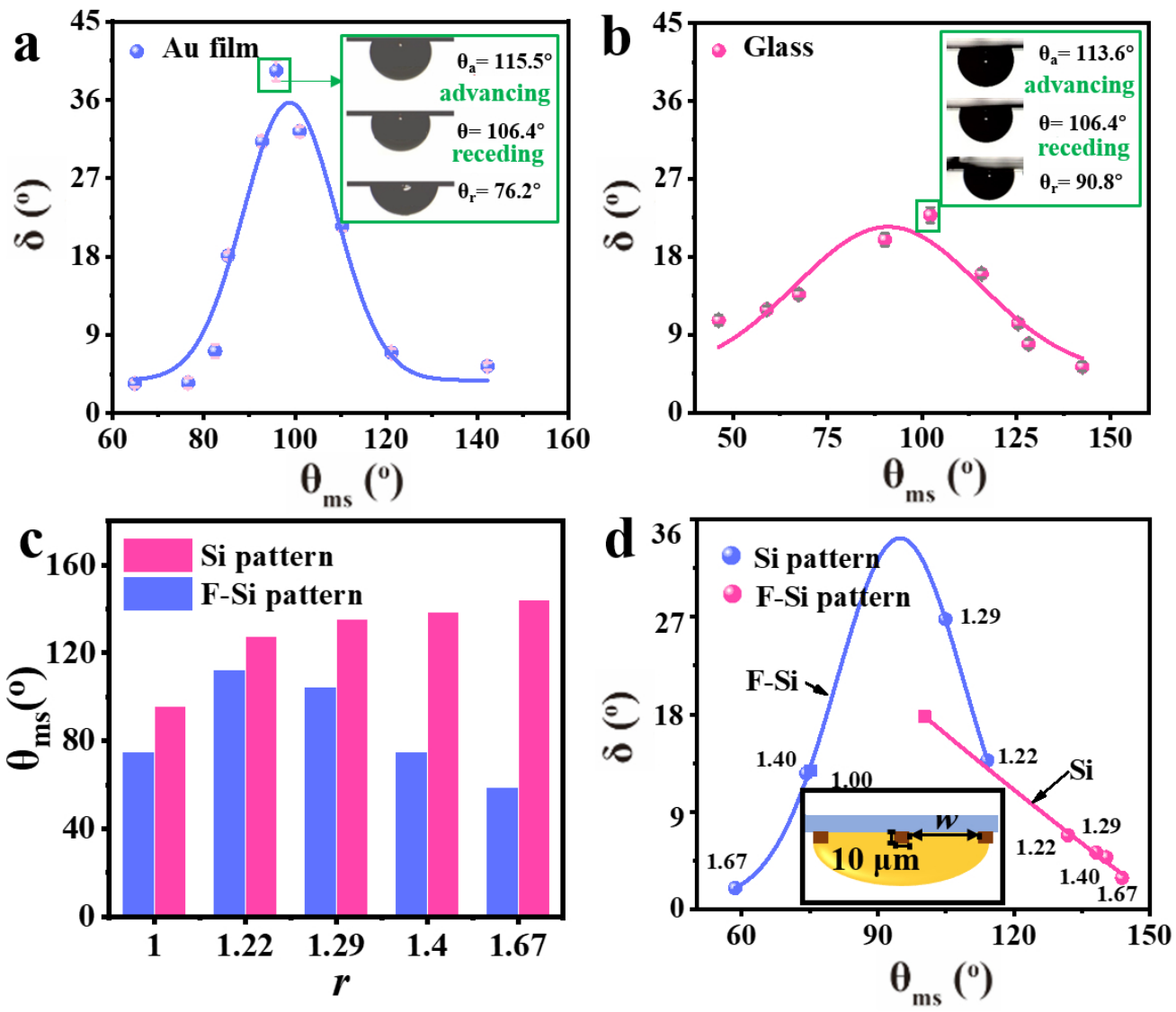

Figure 2. a) The relationship between $\theta \mathrm{ms}$ and $\delta$ for bubbles on the Au film with the modulated wettabilities. Inset: The snapshots of varied states of bubble on a given Au film surface with the $\theta m s \sim 90^{\circ}$. b) The relationship between $\theta \mathrm{ms}$ and $\delta$ for bubbles on glass film surfaces with the modulated wettabilities. Inset: The snapshots of varied states of bubble on a given Au film surface with the $\theta \mathrm{ms} \sim 90^{\circ}$. c) The histogram of $\theta \mathrm{ms}$ with $r$ on the structured micro-grooved Si and F-Si pattern surfaces. d) The plots of $\delta$ with $\theta \mathrm{ms}$ variations for bubbles on the structured micro-grooved $\mathrm{Si}$ and F-Si pattern surfaces. The square points are $\delta$ of F-Si and Si surfaces. Solid line and dots are fitted and experimental results, respectively. Inset: The side view of the pattern surfaces.

$306 \times 264 \mathrm{~mm}(96 \times 96$ DPI) 
a
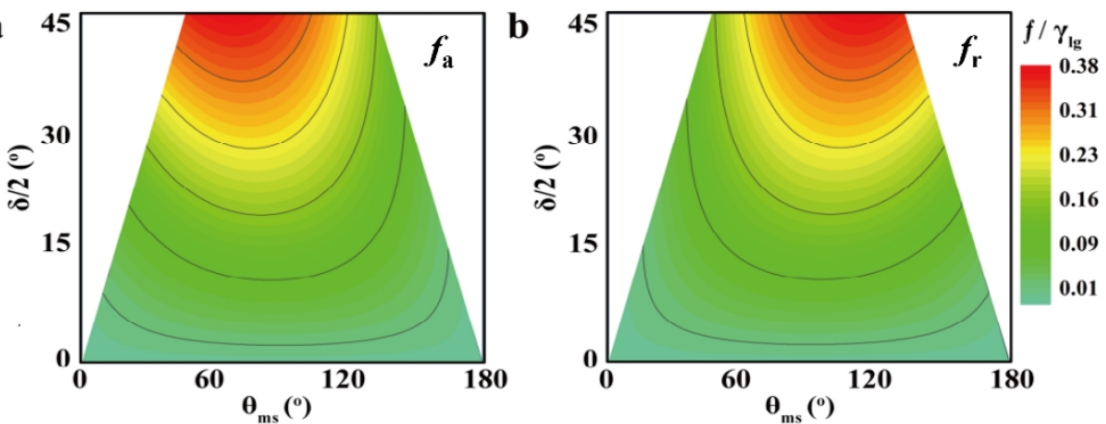

c
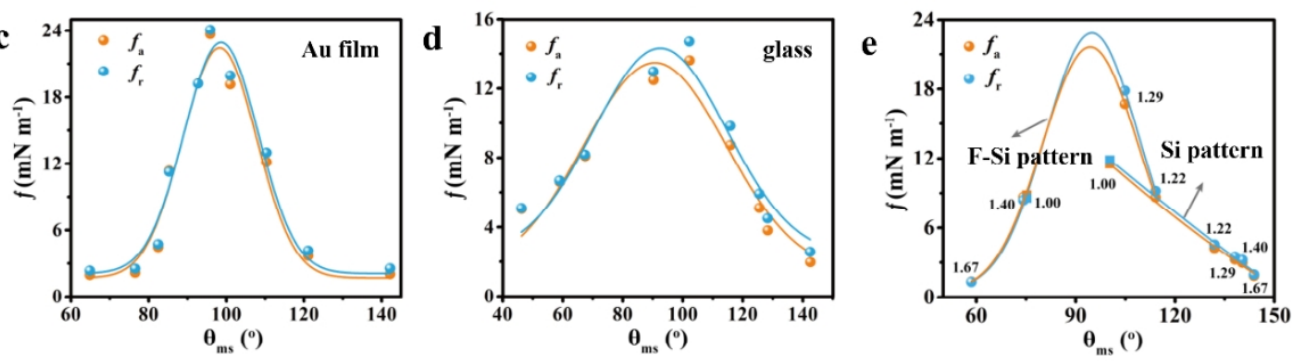

Figure 3. Numerical simulation of the relationship between $f, \delta$ and $\theta m s: a)$ advancing and $b$ ) receding processes for bubbles on the solid surfaces with different wettabilities. $c, d, e)$ Plots of $f$ as a function of $\theta$ ms for bubbles on the Au films, glass and structured micro-grooved Si and F-Si pattern surfaces with varied wettabilities during the bubble advancing and receding processes, respectively. 

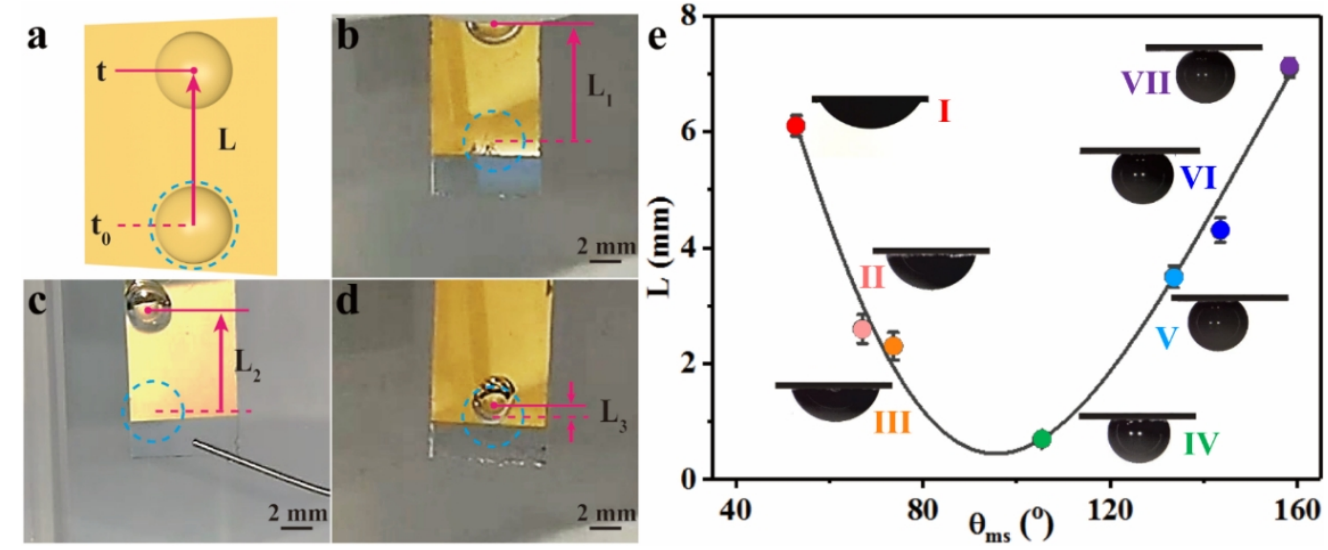

Figure 4. a) Schematic illustration of the sliding distance $(L)$ at the time slots ( $t-t 0)$ for underwater gas bubbles adhering on vertical Au film surfaces. The sliding distance within 5 seconds of underwater bubbles on Au film surfaces with $\theta$ ms: b) 158.30 , c) 52.90 , and d) 105.40 . e) Plot of $L$ as a function of $\theta m s$ for the evolution of underwater gas bubbles. The inserts are snapshots of bubble contact angle on the Au surfaces having different wettabilities.

$139 \times 58 \mathrm{~mm}(220 \times 220 \mathrm{DPI})$ 

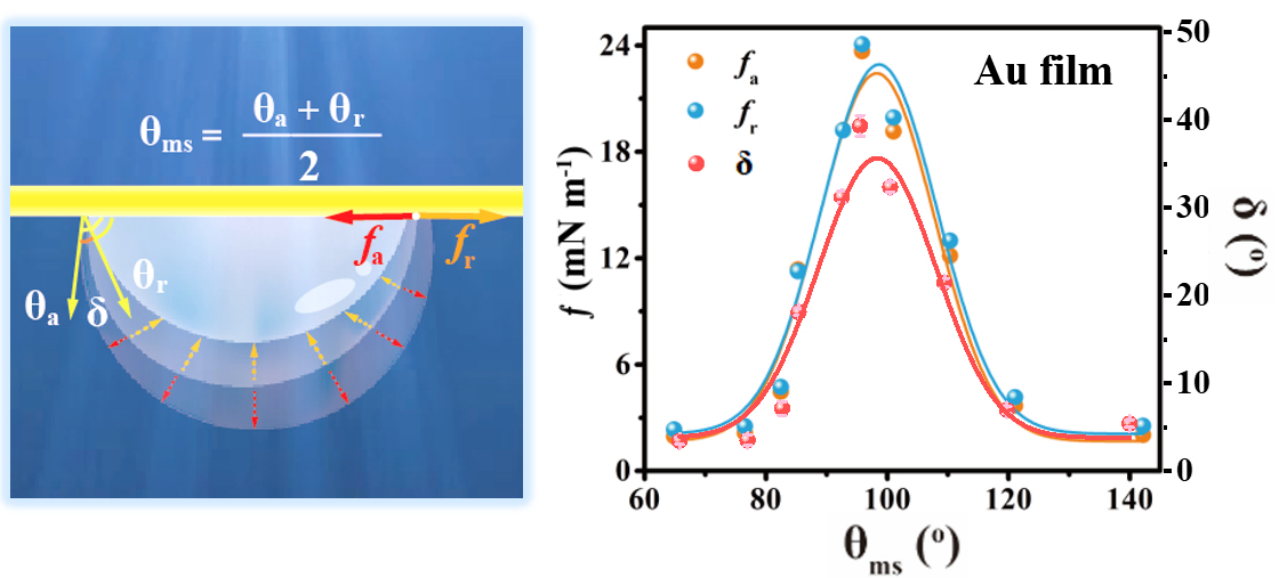

$301 \times 136 \mathrm{~mm}(96 \times 96$ DPI) 